\title{
All smiles for Gulval school community
}

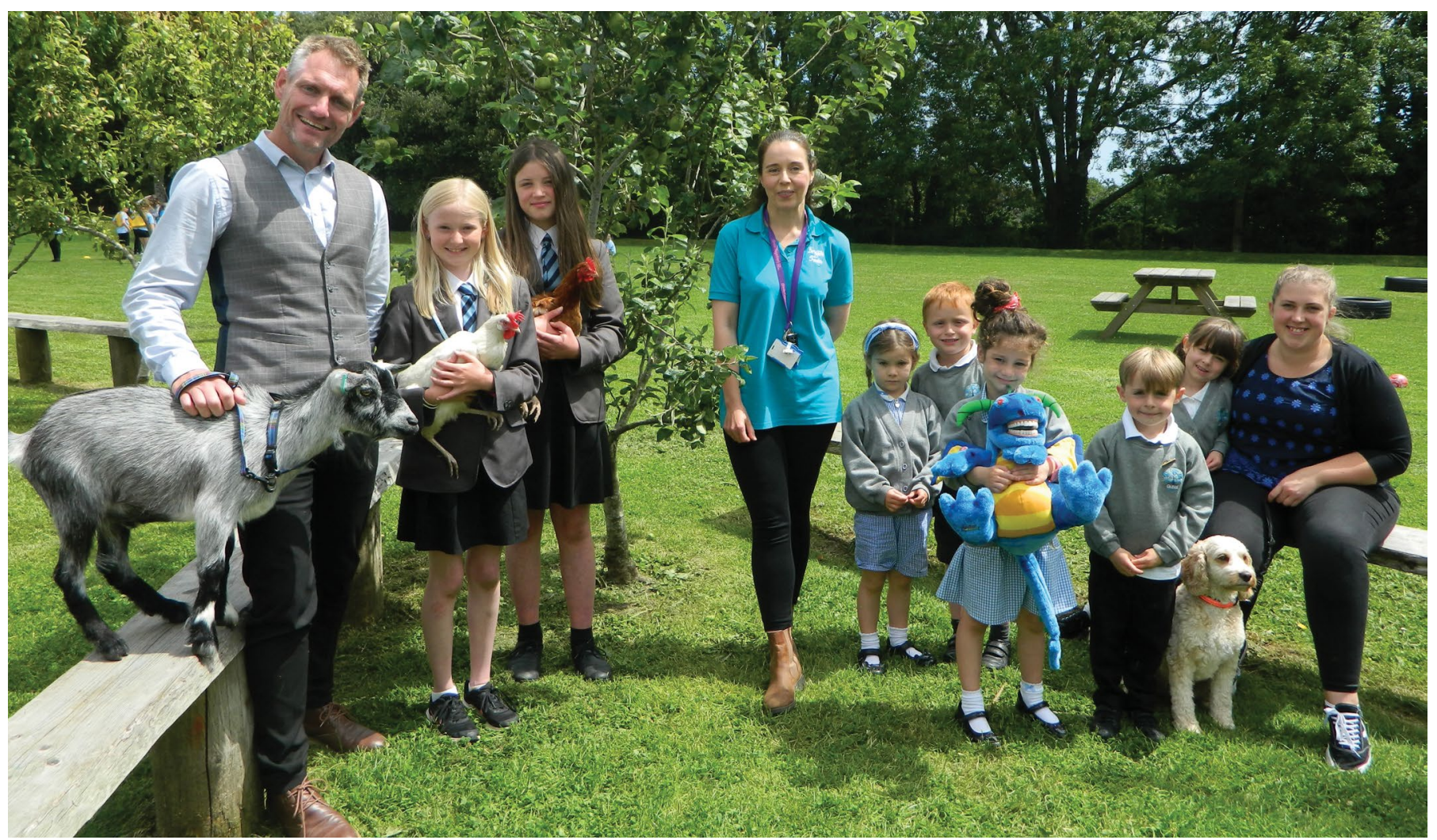

Caption: From left to right: Head Teacher Paul Baker from Gulval School and Jo Trevelyan of the Brighter Smiles Oral Health Team at Smile Together with children from the school and some of their school animals

Almost 200 more children in the west of Cornwall will be improving their oral health thanks to the support of Cornish Pirates, Dental Directory and their partner networks.

Brighter Smiles, Cornwall's oral health programme, will be delivered in Gulval School and Nursery, Penzance from September 2021 thanks to funding from Dental Directory and their key dental suppliers SDI, Acteon UK, Stockdale Martin/Oralieve and W\&H UK Ltd, who have grouped together to fund this Cornish school community.

Programme delivery in the school has been further enabled by a charitable donation from Cornish Pirates' supporters, raised during one of their pre-pandemic home games.

Toothbrushing clubs will be set up in Gulval School nursery and reception classes, fluoride varnish will be applied to the teeth of reception and year 1 pupils, and oral health education delivered to all the schools' pupils with home education packs for the whole family to encourage good oral healthcare at home.

\section{BDA AGM}

The BDA Yorkshire Branch AGM will be held on Tuesday 19 October 2021 at 19:00 at The Bridge Hotel, Walshford (near Wetherby), LS22 5HS.

All BDA members welcome. For further information and to book please visit www.bda.org/bse. 